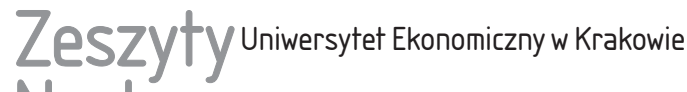 Naukowe
}

\section{Dziedzictwo kulturowe a idea uczenia sie przez całe życie. Wybrane doświadczenia krajów europejskich}

\section{Streszczenie}

Celem artykułu było przeprowadzenie studiów literaturowych przybliżających europejskie doświadczenia w zakresie realizacji projektów edukacyjnych wykorzystujących dziedzictwo kulturowe oraz analiza i agregacja ich efektów, a także ocena, w jakim stopniu wykorzystanie dziedzictwa zwiększa poziom efektów edukacyjnych oraz czy przyczynia się do uzyskania innych efektów. Analiza wykazała, że działania wykorzystujące dziedzictwo tworzą aktywności wpisujące się w ideę uczenia się przez całe życie. Poprzez rozwój osobisty uczestników przyczyniają się do ich: włączenia społecznego, rozwoju więzi społecznych, wzrostu zaangażowania obywatelskiego, rozwoju postaw przedsiębiorczych. Szczególnie dobre efekty uzyskiwane są w pracy z osobami z grup wykluczonych i cechującymi się kreatywnością oraz osobami zainteresowanymi kulturą i historią. Oprócz efektów edukacyjnych projekty przyczyniają się do zachowania lub polepszenia stanu zasobu dziedzictwa kulturowego.

Słowa kluczowe: dziedzictwo kulturowe, kultura, uczenie się przez całe życie, kluczowe kompetencje.

Klasyfikacja JEL: Z18, J68.

Dominika Hołuj, Uniwersytet Ekonomiczny w Krakowie, Wydział Gospodarki i Administracji Publicznej, Katedra Historii Gospodarczej i Społecznej, ul. Rakowicka 27, 31-510 Kraków, e-mail: holujd@uek.krakow.pl, ORCID: https://orcid.org/0000-0001-8532-4052. 


\section{Wprowadzenie}

W przyjętej w 1972 r. konwencji UNESCO za dziedzictwo kulturowe uznano: zabytki, zespoły oraz miejsca zabytkowe o wyjątkowej powszechnej wartości historycznej, estetycznej i naukowej. Obecnie katalog ten obejmuje również dziedzictwo niematerialne (praktyki, przekazy, umiejętności) (Konwencja... 2005), miejsca pamięci (Nora 1989), czy też (w najszerszej definicji) wszelkie materialne i niematerialne efekty działalności człowieka, które obecnie żyjący chcą przyjąć (odziedziczyć), zachować w pamięci (Ashworth 2007, Graham 2009, Howard 2009). Uznawanie zasobu za dziedzictwo jest procesem dynamicznym, dlatego zasób uważany za bezwartościowy z czasem może zostać uznany za cenny (Affelt 2008, Throsby 2010). Dziedzictwo kulturowe jest ważnym nośnikiem tożsamości, pamięci (ma wartość kulturową), a także zasobem, na bazie którego powstają dobra i usługi rynkowe (ma wartość rynkową). Znaczenie dziedzictwa dla społeczeństwa i gospodarki stanowi coraz częściej przedmiot studiów naukowych (Towse 2002, Bowitz i Ibenholt 2009, Throsby 2010, Murzyn-Kupisz 2012). Prowadzone są m.in. analizy jego wpływu na efektywność projektów edukacyjnych, w tym tych wpisujących się w realizację idei uczenia się przez całe życie (lifelong learning - dalej: LLL).

Dla potrzeb niniejszego artykułu przyjęto, że LLL jest środkiem osiągania takich celów, jak: rozwój osobisty, włączenie społeczne, tworzenie więzi społecznych, wzrost zaangażowania obywatelskiego, rozwiązywanie problemów na rynku pracy (Making... 2001). Idea LLL zakłada nabywanie wiedzy, rozwijanie umiejętności i kompetencji. Badacze podkreślają znaczenie dziedzictwa w dążeniu do celów, zwracając jednak uwagę, że wciąż nie uzyskano pełnej wiedzy na temat osiąganych efektów projektów, gdyż skupiono się na edukacji formalnej (Lifelong Learning... 2007, Innocent 2009, Lifelong Learning... 2009, Zipsane 2013).

W artykule dokonano analizy literatury dotyczącej europejskich doświadczeń w zakresie realizacji projektów wykorzystujących dziedzictwo kulturowe ${ }^{1}$. Przeprowadzono także analizę efektów tych działań oraz podjęto próbę oceny, jak bardzo dziedzictwo przyczynia się do zwiększenia efektów projektów edukacyjnych i czy pozwala na przedstawienie dodatkowych efektów (niemożliwych do osiągnięcia w projektach bez zaangażowania dziedzictwa).

${ }^{1} \mathrm{~W}$ artykule wykorzystano źródła zagraniczne ze względu na zakres przypadków objętych badaniem. W Polsce analizowaną tematyką zajmują się m.in. D. Folga-Januszewska, P. Jaskanis, R. Pater, J. Skutnik, M. Szeląg, E. Zduńczyk. 


\section{Idea uczenia się przez całe życie a dziedzictwo kulturowe}

Idea LLL rozwinęła się w okresie powojennym. W latach 50. XX w. tematem zainteresowało się UNESCO, a od lat 90. XX w. - OECD (Lifelong Learning... 1996). Problematyka widoczna jest też w pracach Unii Europejskiej, która w 2006 r. poparła zdobywanie kluczowych kompetencji nabywanych w procesie uczenia się przez całe życie (Key Competences... 2006). Wzrastające znaczenie LLL wynika m.in. z wymagań i uwarunkowań funkcjonowania współczesnego rynku pracy. Obecnie często zmienia się zarówno miejsce pracy, jak i zawód. Znaczenie mają też procesy demograficzne. Życie ulega wydłużeniu, zatem wiedza zdobyta w młodości z czasem staje się niewystarczająca. Potrzeba uczenia się przez całe życie wiąże się też ze zmianami wymagań względem pracowników. Wśród poszukiwanych umiejętności pracowniczych wymienia się obecnie: samodzielną organizację pracy, dostosowanie do zmieniających się warunków, pracę w grupie, prowadzenie dyskusji, umiejętności komunikacyjne i analityczne, matematyczne, językowe, obsługi komputera, kreatywność, podejście ukierunkowane na rozwiązywanie problemów, otwartość na odmienne, nowe idee, przedsiębiorczość (Jackson 2010).

Kolejną istotną okolicznością rozwoju idei LLL jest wzrost znaczenia samodoskonalenia z wewnętrznych pobudek, niepowiązanych z przymusem (np. wymaganiami rynku pracy). Rozwój osobisty stał się wartością samą w sobie. Uczestnicy działań edukacyjnych nie zawsze oczekują, że ich efektem będą korzyści finansowe. Dążenie do dobrobytu zostaje zastąpione przez dążenie do dobrostanu jednostki, satysfakcji z nowych doświadczeń, wspomnień, emocji, relacji społecznych, rozwoju poczucia przynależności do wspólnoty (The Impact... 2009, Fristrup i in. 2012).

Potencjał dziedzictwa w realizacji LLL przejawia się w możliwościach organizacji aktywności o zindywidualizowanym charakterze (dopasowanych do lokalnych kontekstów kulturowych) oraz projektów łączących elementy sformalizowanej nauki ze swobodą wykorzystania nabytej wiedzy i umiejętności (The Impact... 2009, Learning in Museums... 2015). Stąd ich lepszy odbiór i rezultaty w przypadku udziału: indywidualistów, młodzieży i dorosłych o szczególnych cechach, potrzebach, problemach (np. NEET), pokolenia „millenialsów” (poszukujących przeżyć i doświadczeń, a nie kolejnych dóbr materialnych), ludzi „przesyconych” technologią (Zipsane 2008, Fristrup i in. 2012, Millenials... 2014, Sunderland Bowe 2016). Dziedzictwo można wykorzystać do tzw. uczenia włączającego (Deklaracja... 1997, Lifelong Learning... 2007), obejmującego społeczności wykluczone: etnicznie, religijnie, technologicznie, niepełnosprawnych, grupy $\mathrm{z}$ wyuczoną bezradnością. Elementem realizacji tej funkcji są działania z zakresu edukacji multikulturowej, np. praca z mniejszościami lub praca mająca na celu 
zmniejszenie uprzedzeń na tle kulturowym (Lifelong Learning... 2007). Dziedzictwo stwarza możliwość rozwijania umiejętności, wiedzy i kompetencji u ludzi pasjonujących się nim. Pasjonaci z własnej woli uczestniczą w kulturze jako wolontariusze w zamian za nową wiedzę, umiejętności itp. Czynności związane z zainteresowaniami mogą zostać na tyle perfekcyjnie opanowane, że stają się „drugim” zawodem (serious leisure) (Christidou i Hansen 2015). Zaangażowanie udaje się także rozbudzić w grupach wykluczonych czy problemowych (Stebbins 2015).

Aby osiągać założone rezultaty edukacyjne, projekty powinny: nauczać na przykładach, tworzyć możliwości samodzielnego doświadczania i odkrywania, zachęcać do dyskusji, odbywać się w „naturalnym” środowisku, np. w obiektach historycznych (Jackson i Kidal 2008). Uczenie powinno być tak zorganizowane, aby uczniowie mogli sami dostrzec sens swoich działań, co wzmaga chęć uczenia się (Bauer i in. 2011).

T. Fristrup (zob. Fristrup i in. 2012) uważa, że w edukacji opierającej się na dziedzictwie osiągane są dwa rodzaje efektów: wzrost wiedzy oraz rozwój uniwersalnych umiejętności i kompetencji zawdzięczanych dziedzictwu. Najczęściej rozpoznawanym wpływem edukacji z zakresu dziedzictwa jest rozwój kreatywności, stanowiącej istotny współczesny potencjał rozwojowy (Zipsane 2013).

Najpopularniejszą klasyfikacją efektów kształcenia z wykorzystaniem dziedzictwa jest układ tzw. kluczowych kompetencji w procesie LLL (Key Competences... 2006), do których należą: porozumiewanie się w języku ojczystym, porozumiewanie się w językach obcych, kompetencje matematyczne i podstawowe kompetencje naukowo-techniczne, kompetencje informatyczne, umiejętność uczenia się, kompetencje społeczne i obywatelskie, inicjatywność i przedsiębiorczość, świadomość i ekspresja kulturalna. H. Zipsane (2008) uznaje, że dziedzictwo kulturowe tworzy bardzo dobre środowisko kształtowania tych kompetencji.

\section{Przykładowe europejskie projekty wykorzystujące dziedzictwo kulturowe do nieformalnych i pozaformalnych działań edukacyjnych}

Próba badawcza stanowi przegląd projektów z zakresu edukacji nieformalnej (odbywających się poza formalnym systemem szkolnictwa) oraz edukacji pozaformalnej (gdzie pierwotne cele projektu nie były nastawione na uzyskanie efektu edukacyjnego, a jednak taki efekt został wywołany). Przykłady zaczerpnięto głównie z krajów skandynawskich, w dalszej kolejności z Europy Zachodniej oraz, 
w mniejszym zakresie, z Europy Środkowej i Wschodniej². Struktura analizowanej próby ilustruje faktyczne zróżnicowanie poszczególnych obszarów Europy w zakresie zainteresowania wykorzystaniem dziedzictwa do celów edukacji nieformalnej i pozaformalnej3 ${ }^{3}$. Badano aktywności młodzieży i osób dorosłych w wieku produkcyjnym. Z licznych projektów wybrano te, które w najpełniejszy sposób obrazują różnorodność tematyczną inicjatyw edukacyjnych wykorzystujących dziedzictwo oraz które przez organizatorów zostały objęte badaniem efektów. Dobór próby pozwolił na wnioskowanie w zakresie szczególnej roli dziedzictwa w osiąganiu efektów działań edukacyjnych. Analizowane przykłady podzielono na grupy uwzględniające główne cele projektów wskazywane przez organizatorów.

Tabela 1. Projekty związane z tradycyjnymi technikami wytwarzania, odnową i konserwacją obiektów historycznych, pracami archeologicznymi (grupa 1)

\begin{tabular}{|l|l|l|}
\hline \multicolumn{1}{|c|}{ Projekt (beneficjenci) } & \multicolumn{1}{|c|}{ Organizatorzy } & \multicolumn{1}{c|}{ Charakterystyka } \\
\hline $\begin{array}{l}\text { Classes d'éveil au Patri- } \\
\text { moine et à ses metiers } \\
\text { - au centre La Paix-Dieu } \\
\text { (młodzież) }\end{array}$ & $\begin{array}{l}\text { Instytut Dziedzictwa } \\
\text { Kulturowego Walonii, } \\
\text { Belgia }\end{array}$ & $\begin{array}{l}\text { Teoretyczna i praktyczna nauka technik } \\
\text { konserwatorskich w odrestaurowywanym } \\
\text { klasztorze cysterskim }\end{array}$ \\
\hline $\begin{array}{l}\text { Jugendbauhütten } \\
\text { (młodzież, studenci, } \\
\text { młodzi pracujący) }\end{array}$ & $\begin{array}{l}\text { Deutsche Stiftung } \\
\text { Denkmalschutz (NGO), } \\
\text { Niemcy }\end{array}$ & $\begin{array}{l}\text { Teoretyczna i praktyczna nauka technik kon- } \\
\text { serwatorskich i tradycyjnych rzemiosł budow- } \\
\text { lanych realizowana w obiektach historycznych }\end{array}$ \\
\hline $\begin{array}{l}\text { Care and Repair } \\
\text { (NEET) }\end{array}$ & $\begin{array}{l}\text { Agencja rozwoju gospo- } \\
\text { darczego w Peterbo- } \\
\text { rough, Peterborough } \\
\text { Regional College, } \\
\text { English Heritage (NGO), } \\
\text { Rada Miasta, Anglia }\end{array}$ & $\begin{array}{l}\text { Teoretyczna i praktyczna nauka rzemiosł } \\
\text { budowlanych oraz odnawiania obiektów } \\
\text { (np. murów wykonanych tradycyjną techniką } \\
\text { „kamień bez zaprawy”) }\end{array}$ \\
\hline $\begin{array}{l}\text { Szkolenia w techni- } \\
\text { kach archeologicznych } \\
\text { (więźniowie) }\end{array}$ & $\begin{array}{l}\text { Rebibbia Nuovo Com- } \\
\text { plesso Roma (więzienie); } \\
\text { Spółdzielnia Socjalna; } \\
\text { European Centre for } \\
\text { Cultural Organisation } \\
\text { and Management, } \\
\text { Włochy }\end{array}$ & $\begin{array}{l}\text { Szkolenie teoretyczne i praktyczne dla więź- } \\
\text { niów asystujących w pracach archeologicz- } \\
\text { nych prowadzonych na terenie zakładu }\end{array}$ \\
\hline
\end{tabular}

${ }^{2}$ W doborze nie uwzględniono działań prowadzonych w Polsce, co nie oznacza braku krajowych doświadczeń w tym zakresie. Szerzej np. (Edukacja muzealna... 2012).

${ }^{3}$ Badania J.Š. González (2013, s. 9) przeprowadzone na próbie 416 instytucji kultury ze wszystkich krajów europejskich wskazują, że w krajach skandynawskich ok. 70\% ankietowanych instytucji dostrzega swoją edukacyjną rolę w społeczeństwie, zaś w Europie Środkowej i Wschodniej jedynie ok. $40 \%$. 
cd. tabeli 1

\begin{tabular}{|c|c|c|}
\hline Projekt (beneficjenci) & Organizatorzy & Charakterystyka \\
\hline \begin{tabular}{|l|} 
Kształcenie wolontariu- \\
szy w pracach konser- \\
watorskich (długotrwale \\
bezrobotni, NEETS, \\
osoby z trudnościami \\
edukacyjnymi)
\end{tabular} & $\begin{array}{l}\text { The Conservation } \\
\text { Volunteers (NGO), } \\
\text { Anglia }\end{array}$ & $\begin{array}{l}\text { Teoretyczna i praktyczna nauka w zakresie } \\
\text { konserwacji przestrzeni publicznych zago- } \\
\text { spodarowanych historycznymi elementami } \\
\text { (np. popularnymi w Anglii kamiennymi } \\
\text { murami) }\end{array}$ \\
\hline $\begin{array}{l}\text { Conservation Volunteers } \\
\text { (brak ograniczeń) }\end{array}$ & $\begin{array}{l}\text { ELIX Learning Center, } \\
\text { Grecja }\end{array}$ & $\begin{array}{l}\text { Obozy kształcące w zakresie kultury, sztuki, } \\
\text { archeologii i prac renowacyjnych }\end{array}$ \\
\hline $\begin{array}{l}\text { Academy of Craft } \\
\text { (brak ograniczeń) }\end{array}$ & $\begin{array}{l}\text { muzea (Węgry, Słowe- } \\
\text { nia) }\end{array}$ & $\begin{array}{l}\text { Warsztaty rękodzieła (ginące zawody). Lekcje } \\
\text { muzealne i zwiedzanie }\end{array}$ \\
\hline $\begin{array}{l}\text { Adoptoi monumentti } \\
\text { (brak ograniczeń) }\end{array}$ & $\begin{array}{l}\text { Muzeum prowincji } \\
\text { Pirkanmaan, Finlandia }\end{array}$ & $\begin{array}{l}\text { Projekt dobrowolnej ,,adopcji” zabytku } \\
\text { budowlanego lub archeologicznego. Obejmuje: } \\
\text { prace remontowe, gromadzenie informacji } \\
\text { o obiekcie, organizowanie wydarzeń dotyczą- } \\
\text { cych obiektu. Gwarancja wsparcia pracowni- } \\
\text { ków muzeum, archeologów, konserwatorów }\end{array}$ \\
\hline $\begin{array}{l}\text { Handicrafts for all (brak } \\
\text { ograniczeń) }\end{array}$ & $\begin{array}{l}\text { Muzeum w Stundar, } \\
\text { Finlandia }\end{array}$ & $\begin{array}{l}\text { Kursy wytwarzania tradycyjnych wyrobów } \\
\text { rzemieślniczych (garncarstwo, kowalstwo) }\end{array}$ \\
\hline $\begin{array}{l}\text { Model Halland - Kurs } \\
\text { tradycyjnego rzemiosła } \\
\text { i remont obiektu } \\
\text { (bezrobotni w zawodach } \\
\text { związanych z budownic- } \\
\text { twem) }\end{array}$ & $\begin{array}{l}\text { Instytucje publiczne zaj- } \\
\text { mujące się dziedzictwem } \\
\text { kulturowym i rynkiem } \\
\text { pracy, firmy budowlane } \\
\text { i szkoleniowe, Szwecja }\end{array}$ & $\begin{array}{l}\text { Państwowy program aktywizacji zawodowej } \\
\text { (kursy tradycyjnych rzemiosł budowlanych, } \\
\text { w tym stosowania tradycyjnych materiałów) } \\
\text { połączony z ratowaniem obiektów historycz- } \\
\text { nych }\end{array}$ \\
\hline $\begin{array}{l}\text { Reaktywacja upraw } \\
\text { dawnych odmian żyta } \\
\text { (brak ograniczeń) }\end{array}$ & $\begin{array}{l}\text { Lietuvos liaudies buities } \\
\text { muziejus (skansen), } \\
\text { Litwa }\end{array}$ & $\begin{array}{l}\text { Szkolenie z zakresu historycznej, obecnie } \\
\text { nieomal zupełnie zapomnianej, organizacji } \\
\text { uprawy dawnych odmian żyta, pieczenia } \\
\text { z mąki żytniej chleba, budowania pieca } \\
\text { chlebowego }\end{array}$ \\
\hline
\end{tabular}

Źródło: opracowanie własne na podstawie (Lifelong Learning... 2007, Gustaffson 2011, Zipsane 2012, Fristrup i in. 2012, Hunt i Kershaw 2013, Birgisdóttir 2014, The Conservation Volunteers.... 2016, Haapalainen i in. 2016, Haverkamp i Strauch 2017).

Tabela 2. Projekty mające na celu likwidację wykluczeń społecznych związanych z wielokulturowością społeczeństw (grupa 2)

\begin{tabular}{|c|c|c|}
\hline Projekt (beneficjenci) & Organizatorzy & Charakterystyka \\
\hline $\begin{array}{l}\text { Towards an active } \\
\text { democracy with } \\
\text { Theatre in Education } \\
\text { (młodzież z mniejszości } \\
\text { kulturowych, ze środo- } \\
\text { wisk wykluczonych) }\end{array}$ & $\begin{array}{l}\text { Magyar Drámapeda- } \\
\text { gógiai Társaság (NGO), } \\
\text { Węgry, Słowacja, Serbia }\end{array}$ & $\begin{array}{l}\text { Tworzenie sztuk teatralnych o tematyce } \\
\text { prezentującej podstawowe wartości demokra- } \\
\text { tyczne młodzieży wywodzącej się z mniejszości } \\
\text { kulturowych }\end{array}$ \\
\hline
\end{tabular}


cd. tabeli 2

\begin{tabular}{|l|l|l|}
\hline \multicolumn{1}{|c|}{ Projekt (beneficjenci) } & \multicolumn{1}{|c|}{ Organizatorzy } & \multicolumn{1}{c|}{ Charakterystyka } \\
\hline $\begin{array}{l}\text { The Swiss Lernfe- } \\
\text { stival 2013 Zürich } \\
\text { (Szwajcarzy, emigranci) }\end{array}$ & $\begin{array}{l}\text { Swiss Adult Education } \\
\text { Association (NGO); } \\
\text { Turkish Society } \\
\text { Switzerland (NGO), } \\
\text { Szwajcaria }\end{array}$ & $\begin{array}{l}\text { Prezentacje wzajemne kultur: szwajcarskiej } \\
\text { i kultury, których reprezentanci zamieszkują } \\
\text { Szwajcarię (np. muzułmanie) }\end{array}$ \\
\hline $\begin{array}{l}\text { Changing Horizons - } \\
\text { Secrets of the New City } \\
\text { (mniejszości kulturowe) }\end{array}$ & $\begin{array}{l}\text { Fabrevieux - Atelier } \\
\text { aktywności artystycz- } \\
\text { nych, Holandia }\end{array}$ & $\begin{array}{l}\text { Przygotowanie przedstawień teatralnych } \\
\text { i innych sztuk wizualnych dotyczących historii } \\
\text { procesów migracyjnych }\end{array}$ \\
\hline $\begin{array}{l}\text { Xberg-Tag - Podróż do } \\
\text { multikulturowego Ber- } \\
\text { lina (brak ograniczeń) }\end{array}$ & $\begin{array}{l}\text { Muzeum Dzielnicy } \\
\text { Friedrichshain - } \\
\text { Kreuzberg; aktywiści, } \\
\text { Niemcy }\end{array}$ & $\begin{array}{l}\text { Zwiedzanie multikulturowej dzielnicy Berlina } \\
\text { poznawanie kultur ją zamieszkujących. Dysku- } \\
\text { sja o uprzedzeniach kulturowych. Przewodnicy } \\
\text { - emigranci }\end{array}$ \\
\hline $\begin{array}{l}\text { Sieć dla różnorodności } \\
\text { (mniejszości kulturowe) }\end{array}$ & muzea w Norwegii & $\begin{array}{l}\text { Rekrutacja ludzi reprezentujących mniejszość } \\
\text { kulturową do pracy w sektorze muzealnym } \\
\text { (wcześniej był on zdominowany rodzimymi } \\
\text { Norwegami). Projekt obejmuje praktyki } \\
\text { w muzeum (dokumentacja, rejestracja, utrzyma- } \\
\text { nie zbiorów) }\end{array}$ \\
\hline $\begin{array}{l}\text { Wystawa Latjo Drom } \\
\text { (Norwegowie, w tym } \\
\text { przedstawiciele spo- } \\
\text { łeczności romskiej) }\end{array}$ & $\begin{array}{l}\text { Glomsdal Museum } \\
\text { w Norwegii }\end{array}$ & $\begin{array}{l}\text { Wystawa, dni rzemiosła, koncerty prezentujące } \\
\text { kulturę romską oraz doświadczenia narodu } \\
\text { romskiego w zakresie dyskryminacji kulturowej }\end{array}$ \\
\hline $\begin{array}{l}\text { Archiwa Multikultu- } \\
\text { rowe w Oslo (mniej- } \\
\text { szości kulturowe) }\end{array}$ & $\begin{array}{l}\text { Archiwum Miejskie } \\
\text { w Oslo, Norwegia }\end{array}$ & $\begin{array}{l}\text { Tworzenie zasobu archiwalnego dotyczącego } \\
\text { historii mniejszości narodowych w Oslo } \\
\text { we współpracy z przedstawicielami tych mniej- } \\
\text { szości }\end{array}$ \\
\hline
\end{tabular}

Źródło: opracowanie własne na podstawie (Lifelong Learning... 2007, Fristrup i in. 2012) oraz Swiss Lernfestival 2013 - Living Cultures, materiały promocyjne.

Tabela 3. Projekty mające na celu włączenie społeczne i zawodowe, w tym osób bezrobotnych oraz grup problemowych (grupa 3)

\begin{tabular}{|l|l|l|}
\hline \multicolumn{1}{|c|}{ Projekt (beneficjenci) } & \multicolumn{1}{|c|}{ Organizatorzy } & \multicolumn{1}{c|}{ Charakterystyka } \\
\hline $\begin{array}{l}\text { Xpress on TraX } \\
\text { (zmieniona na The Back } \\
\text { on Track) (bezrobotni; } \\
\begin{array}{l}\text { 20-25 lat, bez istotnego } \\
\text { doświadczenia zawodo- } \\
\text { wego) }\end{array}\end{array}$ & $\begin{array}{l}\text { The Nordic Centre } \\
\text { of Heritage Learning, } \\
\text { Muzeum Regionalne } \\
\text { Jamtli, Regionalne } \\
\text { Archiwa w Östersund, } \\
\text { Szwecja }\end{array}$ & $\begin{array}{l}\text { Angażowanie bezrobotnych w działania insty- } \\
\text { tucji kultury oraz inne aktywności kulturalne }\end{array}$ \\
\hline $\begin{array}{l}\text { Ikon Youth Programme } \\
\text { (młodzież) }\end{array}$ & $\begin{array}{l}\text { Ikon Gallery, Birming- } \\
\text { ham (NGO), Anglia }\end{array}$ & $\begin{array}{l}\text { Praca w muzeum (tworzenie sztuki, praca } \\
\text { z artystami, organizacja wydarzeń w muzeum, } \\
\text { rozwijanie własnych pomysłów) }\end{array}$ \\
\hline
\end{tabular}


cd. tabeli 3

\begin{tabular}{|l|l|l|}
\hline \multicolumn{1}{|c|}{ Projekt (beneficjenci) } & \multicolumn{1}{|c|}{ Organizatorzy } & \multicolumn{1}{c|}{ Charakterystyka } \\
\hline Blikopeners (młodzież) & $\begin{array}{l}\text { Stedelijk Museum, } \\
\text { Holandia }\end{array}$ & $\begin{array}{l}\text { Organizowanie w muzeum różnych wydarzeń } \\
\text { (np. samodzielne przygotowywanie programu } \\
\text { TV na temat sztuki) }\end{array}$ \\
\hline $\begin{array}{l}\text { Domino Effect Project } \\
\text { for NEET Young } \\
\text { People (NEET) }\end{array}$ & $\begin{array}{l}\text { National Portrait } \\
\text { Gallery, Londyn; } \\
\text { Dorset Foundation } \\
\text { sponsor); NGO, } \\
\text { Anglia }\end{array}$ & $\begin{array}{l}\text { Kursy portretowania dla młodzieży niezain- } \\
\text { teresowanej sztuką. W programie biorą udział } \\
\text { uczestnicy równoległego programu Youth } \\
\text { Forum (młodzi, zaangażowani w sztukę), co } \\
\text { ma pokazać, że galeria to miejsce przyjazne } \\
\text { młodzieży }\end{array}$ \\
$\begin{array}{l}\text { Communicating the } \\
\text { museum: innovation, } \\
\text { accessibility, creativity } \\
\text { (NEET, szczególnie } \\
\text { osoby z problemami ze } \\
\text { wzrokiem) }\end{array}$ & $\begin{array}{l}\text { Museo Tattile Statale } \\
\text { Omero, Ancona, } \\
\text { Włochy }\end{array}$ & $\begin{array}{l}\text { Program miał na celu polepszenie komunikacji } \\
\text { muzeum z potencjalnymi odbiorcami (osoby } \\
\text { niewidome, niedowidzące). Działania podej- } \\
\text { mowane przez uczestników obejmowały m.in. } \\
\text { próby tworzenia kanałów informacji dostęp- } \\
\text { nych, czytelnych dla osób z wadami wzroku) }\end{array}$ \\
\hline $\begin{array}{l}\text { Towarzysze Sztuki } \\
\text { i Kultury (osoby wyklu- } \\
\text { czone z uczestnictwa } \\
\text { w kulturze) }\end{array}$ & $\begin{array}{l}\text { Muzea miasta } \\
\text { Jyväskylä, Finlandia }\end{array}$ & $\begin{array}{l}\text { Pomoc wolontariuszy w zmniejszaniu barier } \\
\text { uczestnictwa w kulturze poprzez organizację } \\
\text { pomocy osobom indywidualnym i grupom } \\
\text { w trakcie wydarzeń kulturalnych lub pobytu } \\
\text { w instytucjach kultury (np. niepełnosprawni) }\end{array}$ \\
\hline
\end{tabular}

Źródło: opracowanie własne na podstawie (Fristrup i in. 2012, Learning in Museums...2015).

Tabela 4. Projekty rozwijające umiejętności językowe, redakcyjne (grupa 4)

\begin{tabular}{|l|l|l|}
\hline \multicolumn{1}{|c|}{ Projekt (beneficjenci) } & \multicolumn{1}{|c|}{ Organizatorzy } & \multicolumn{1}{|c|}{ Charakterystyka } \\
\hline $\begin{array}{l}\text { Ringsted - tworzenie } \\
\text { roczników histo- } \\
\text { rycznych (osoby bez } \\
\text { doświadczenia publika- } \\
\text { cyjnego) }\end{array}$ & $\begin{array}{l}\text { Archiwa i Muzeum } \\
\text { Ringstead, Dania }\end{array}$ & $\begin{array}{l}\text { Tworzenie roczników opisujących historię } \\
\text { lokalną (gromadzenie wiadomości od żyjących } \\
\text { starszych mieszkańców). Redaktorami rocznika } \\
\text { byli uczestnicy projektu wspomagani przez } \\
\text { pracowników archiwum }\end{array}$ \\
\hline $\begin{array}{l}\text { Literary Associations } \\
\text { through a historical } \\
\text { landscape (młodzież) }\end{array}$ & $\begin{array}{l}\text { Meadowhead School } \\
\text { and Language College } \\
\text { Dyche Lane, Anglia }\end{array}$ & $\begin{array}{l}\text { Lekcje historii w historycznych obiektach } \\
\text { (Opactwo Whitby). Samodzielne przygotowanie } \\
\text { tekstu dotyczącego historii, publikacja }\end{array}$ \\
\hline St-ART (młodzież) & $\begin{array}{l}\text { Fioretti College in } \\
\text { Lisse, Pieter Nieuwland } \\
\text { College, Cygnus Gym- } \\
\text { nasium in Amsterdam, } \\
\text { Holandia }\end{array}$ & $\begin{array}{l}\text { Wywiady z osobami starszymi na temat historii } \\
\text { ich życia. Dokumentacja wywiadów, przygoto- } \\
\text { wanie relacji }\end{array}$ \\
\hline
\end{tabular}

Źródło: opracowanie własne na podstawie (Bauer i in. 2011, Fristrup i in. 2012, Jensen 2014). 
Tabela 5. Projekty rozwijające umiejętności techniczne, informatyczne, matematyczne (grupa 5)

\begin{tabular}{|l|l|l|}
\hline \multicolumn{1}{|c|}{ Projekt (beneficjenci) } & \multicolumn{1}{|c|}{ Organizatorzy } & \multicolumn{1}{c|}{ Charakterystyka } \\
\hline $\begin{array}{l}\text { Prestegårdslåna (brak } \\
\text { ograniczeń) }\end{array}$ & $\begin{array}{l}\text { NGO, Melhus, } \\
\text { Norwegia }\end{array}$ & $\begin{array}{l}\text { Uratowanie od rozbiórki obiektu dawnej pleba- } \\
\text { nii. Fundacja zarządza i opiekuje się budynkiem }\end{array}$ \\
\hline $\begin{array}{l}\text { Digitalizacja Naro- } \\
\text { dowych Archiwów } \\
\text { (bezrobotni) }\end{array}$ & $\begin{array}{l}\text { Archiwa Narodowe } \\
\text { Islandii }\end{array}$ & $\begin{array}{l}\text { Katalogowanie zbiorów, weryfikowanie pra- } \\
\text { widłowości wcześniejszego skatalogowania, } \\
\text { digitalizacja i upublicznienie w Internecie }\end{array}$ \\
\hline $\begin{array}{l}\text { Archiwizacja i publi- } \\
\text { kacja on-line zasobów } \\
\text { archiwalnych (brak } \\
\text { ograniczeń) }\end{array}$ & $\begin{array}{l}\text { Archiwum Państwowe } \\
\text { i lokalne archiwa, } \\
\text { Dania }\end{array}$ & $\begin{array}{l}\text { Digitalizacja i publikacja w Internecie zasobów } \\
\text { archiwów państwowych }\end{array}$ \\
\hline
\end{tabular}

Źródło: opracowanie własne na podstawie (Clausen i Marker 2000, Fristrup i in. 2012).

\section{Analiza efektów działań edukacyjnych wykorzystujących dziedzictwo kulturowe}

Punktem wyjścia analizy były oddziaływania projektów zidentyfikowane przez ich organizatorów ${ }^{4}$. Należy jednak podkreślić, że są one dość ogólnikowe, często odwołują się do układu kluczowych kompetencji, który w przypadku projektów wykorzystujących dziedzictwo nie jest wystarczający, aby oddać złożoność faktycznie osiągniętych efektów. Rozwijając wnioskowanie przedstawione w literaturze, uznano, że należy w ocenie uwzględnić osiąganie celów, dla jakich organizowane są działania wpisujące się w ideę LLL. Przyjęto też, że wyniki powinny być oceniane w układzie sekwencyjnie pojawiających się oddziaływań oraz powinny dodatkowo uwzględniać efekty niezamierzone. Ponadto uwzględniono efekty inne niż edukacyjne. Przyjęto, że pierwotnym rezultatem wszystkich inicjatyw jest rozwój osobisty uczestników. Wobec tego w każdej z wyodrębnionych grup projektów wskazano najpierw oddziaływania związane z tym wymiarem, a w dalszej kolejności opisano efekty pośrednie i realizowane po zakończeniu projektu.

Projekty z grupy 1 pozwalały nabyć wiedzę i rozwinąć umiejętności w zakresie tradycyjnych technik wytwarzania, odnowy i konserwacji obiektów historycznych, prac archeologicznych. Ze względu na rosnące zainteresowanie dziedzictwem

${ }^{4}$ Syntetyczny opis efektów analizowanych projektów zawarto w opracowaniach: (Clausen i Marker 2000, Lifelong Learning... 2007, Bauer i in. 2011, Gustaffson 2011, Fristrup i in. 2012, Zipsane 2012, Hunt i Kershaw 2013, Birgisdóttir 2014, Jensen 2014, Learning in Museums...2015, The Conservation Volunteers.... 2016, Haapalainen i in. 2017) oraz Swiss Lernfestival 2013 - Living Cultures, materiały promocyjne. 
projekty te stały się pożądane, co wynikało z wewnętrznego przekonania, że dbałość o zasób i tradycję jest swoistym obowiązkiem właściciela (czy wykonawcy prac budowlanych), ale też z chęci dostosowania do oczekiwań inwestorów (np. dokształcenie jako warunek konieczny otrzymania zleceń wymagających stosowania tradycyjnych technik). Uczestnicy projektów reprezentowali obie grupy, więc efekty edukacyjne w ramach rozwoju osobistego mogły być wykorzystane zarówno do:

- realizacji aspiracji zawodowych (uzupełnienia braków w edukacji formalnej ${ }^{5}$, nabycia pierwszych umiejętności zawodowych). Efektem sekwencyjnym uczestnictwa była możliwość realizacji specjalistycznych zleceń i zwiększenie dochodów;

- rozwoju zainteresowań, pasji, odkrywania talentów. Wtedy efekty o charakterze sekwencyjnym mogły nie mieć finansowego wymiaru (choć nie było to wykluczone). Zwiększając zasób wiedzy, wzmacniały poczucie przynależności do wspólnoty kulturowej (jeżeli projekt dotyczył kultury, z której wywodził się uczestnik). Dawały możliwość wykorzystania wiedzy, umiejętności w projektach społecznych (wolontariat), zwiększały zaangażowanie obywatelskie (aktywna postawa wobec działań obniżających wartości kulturowe dziedzictwa).

Efekty indywidualne były więc zależne od cech i oczekiwań każdego z uczestników (stwierdzenie to dotyczy wszystkich grup analizowanych projektów).

Po zakończeniu projektów następowała dyfuzja wiedzy, dobrych praktyk konserwatorskich (uczniowie stawali się nauczycielami, co zwiększało ich poczucie własnej wartości, a jednocześnie wywoływało efekt edukacyjny u kolejnych osób) ${ }^{6}$.

Projekty związane z tradycyjnymi technikami i materiałami przyczyniały się do uzyskania efektów ekonomicznych. Wzrastało zainteresowanie tradycyjnymi produktami oraz narzędziami. Rozwijał się lokalny rynek zbytu, ponieważ techniki tradycyjne opierały się głównie na lokalnych produktach (efekt najbardziej widoczny w projektach skandynawskich). Gdy produkt tradycyjny stawał się coraz popularniejszy, kolejni projektanci byli bardziej skłonni do zastosowania go w nowych obiektach. Ze względu na lokalne pozyskiwanie materiałów, narzędzi, generowane były też efekty ekologiczne (ograniczenie przewozów). W przypadku tego rynku jest to szczególnie istotne, ponieważ w ostatnich dziesięcioleciach miał miejsce trend odwrotny (rynek egzotycznych materiałów budowlanych).

${ }^{5}$ Na przykład w trakcie realizacji modelu Halland zauważono, że w okresie powojennym w Szwecji zaprzestano kształcenia osób zawiązanych z budownictwem w zakresie tradycyjnych technik budowania z zastosowaniem lokalnych materiałów budowlanych - zastosowanie modelu częściowo zniwelowało ten brak.

${ }^{6}$ Na przykład podniesienie samooceny osadzonych w zakładzie karnym w Rzymie. 
Analizowana grupa projektów pozwalała na uzyskiwanie efektów możliwych do osiągnięcia także w projektach bez angażowania dziedzictwa, np. rozwój umiejętności pracy w grupie, umiejętności pozyskiwania funduszy, zmiana postawy wobec nauki i pracy z pasywnej na aktywną. Każdy z wymienionych efektów z czasem wpływał pozytywnie na gospodarkę (mniej bezrobotnych, lepiej wykształceni pracownicy) oraz obniżał koszt prowadzenia polityki społecznej (mniejsze kwoty wypłacanych zasiłków), zwiększał wpływy podatkowe.

Projekty z grupy 2 pozwalały nabyć wiedzę o kulturach, których przedstawiciele współzamieszkują dany obszar, w szczególności w zakresie historii i kultury tych społeczności, w tym kulturowo uwarunkowanymi: etosem pracy, modelem życia rodzinnego czy uczestnictwa w życiu społeczności lokalnej. Przedstawiciele innej kultury realizowali rozwój osobisty poprzez nabycie wiedzy pozwalającej zrozumieć, jakie są przyczyny „niekompatybilności” kultur współzamieszkujących, historyczne uwarunkowania wzajemnej niechęci (weryfikacja stereotypów). Przedstawiciele mniejszości kulturowej, która miała (niekiedy pierwszy raz) szanse zaprezentować się na forum publicznym czy uczestniczyć w projekcie dedykowanym ich kulturze (archiwizacja, staż w instytucji kultury), zwiększali swoją samoocenę, dobrostan psychiczny. Były to oddziaływania bezpośrednie jako efekt projektu na poziomie poszczególnych uczestników projektu.

Zmiana postrzegania przedstawicieli innej kultury czy zaproszenie do udziału w projekcie przewidzianym dla przedstawicieli mniejszości kulturowej stanowiły impuls do: ograniczonej akceptacji współzamieszkiwania, stopniowego włączania społecznego, a w dalszej kolejności (niekiedy) zawiązywania więzi społecznych o charakterze międzykulturowym. Był to efekt na poziomie społeczności.

Rozpoczęcie procesu przełamywania podziałów społecznych w dalszej kolejności generowało też skutki ekonomiczne (emigranci częściej dostawali pracę) dla władz publicznych - zmniejszał się koszt opieki społecznej, a wzrastały wpływy z podatków. Warto w tym miejscu zwrócić uwagę, że emigrantów po realizacji projektów zatrudniano w miejscach, w których wcześniej byli zatrudniani rzadko (np. w instytucjach kultury).

Analizowana grupa projektów pozwalała na uzyskiwanie efektów możliwych do osiągnięcia także w projektach nieangażujących dziedzictwa, tj.: rozwój praktycznych umiejętności dyskusji szanującej uczestników reprezentujących odmienne poglądy i umiejętności osiągania konsensusu. Wprawdzie można je praktykować w innych okolicznościach, jednak w analizowanych projektach różnice i problemy były autentyczne, dyskusji towarzyszyły prawdziwe emocje. Zwiększało to trudność osiągnięcia konsensusu, ale też w efektywny sposób pozwalało na wykształcanie umiejętności.

Projekty z grupy 3 przeznaczone były dla osób bezrobotnych, a także należących do grup problemowych. Praca z tymi grupami może być prowadzona poprzez 
różne projekty, niekoniecznie wykorzystujące dziedzictwo. Rozważając jednak, czy i na ile zaangażowanie tych grup w projekty opierające się na zasobie dziedzictwa dawało dobre (lepsze) efekty, trzeba zwrócić uwagę na źródła problemów (szczególnie osób młodych). Coraz częściej ich przyczyną jest „przesycenie technologią". Rośnie też popularność (i rynek) rozrywek, których celem jest dawanie uczestnikom przeżyć, emocji, doświadczeń (jest to tzw. ekonomia doświadczania). Dla osób poszukujących przeżyć innych niż te, których dostarcza cywilizacja cyfrowa, udział w projekcie wykorzystującym dziedzictwo był atrakcyjny ze względu na „,analogowość” zasobu, dającą nowe, nieznane dotąd przeżycia.

Zauważono też, że dla osób przejawiających talenty artystyczne korzystanie z dziedzictwa stanowiło główny impuls do podjęcia decyzji o uczestnictwie w projektach dających możliwość nabycia wiedzy historycznej, poznania technik artystycznych, poznania warsztatu pracy artysty. Pierwsze doświadczenia i efekty działań artystycznych są szansą na spełnienie marzeń, rozwój talentów artystycznych. Wzrastała samoocena, ale także możliwości zmiany postawy zawodowej z biernej na czynną (dalsze dokształcanie, zarobkowe wykonywanie prac artystycznych).

Niekiedy uczestnictwo w projekcie stanowiło pierwszą w życiu możliwość zaangażowania się w działania kulturalne osobom, które wcześniej miały taką potrzebę, ale ze względu na niską samoocenę (traktowanie kultury jako niedostępnej, jako „innego świata”), czy też brak wzorców uczestnictwa w kulturze wyniesionych z domu rodzinnego - wcześniej nie zdecydowały się na udział w aktywnościach kulturalnych. Dla tej grupy uczestnictwo dawało szanse realizacji marzeń i ambicji. Zdobyte kompetencje uniwersalne (komunikacyjne, językowe, administracyjne) stanowiły jedynie wartość dodaną uczestnictwa, a najważniejsze było poznanie tak dziedzictwa, jak i samej instytucji kultury.

Analizowana grupa projektów pozwalała na uzyskiwanie dalszych efektów możliwych także w projektach bez angażowania dziedzictwa, tj.: rozwoju umiejętności pracy w grupie, kompetencji cyfrowych. Uczestnicy przyswajali wiedzę, umiejętności i kompetencje związane $\mathrm{z}$ administracyjną stroną działania instytucji kultury. Działania zmierzające do likwidacji barier dostępu do instytucji dla osób niepełnosprawnych mogły być też prowadzone w innych okolicznościach. W niektórych przypadkach, jako dodatkowy efekt projektu, wystąpiło zainteresowanie działalnością merytoryczną instytucji kultury, zbudowana została więź pomiędzy instytucją a uczestnikami.

Poprzez rozwój osobisty uczestników (podobnie jak w poprzednich grupach) z czasem występowały efekty sekwencyjne związane z włączeniem społecznym, podjęciem pracy zawodowej, ,,powrotem do edukacji”. Te oddziaływania następnie przekładały się na efekty gospodarcze oraz spadek kosztu prowadzonej przez 
władze publiczne polityki społecznej (podobnie jak we wcześniej analizowanych grupach).

Projekty grupy 4 pozwalały na nabycie i doskonalenie umiejętności: językowych, pisarskich, gromadzenia danych w badaniach terenowych, przygotowania tekstu do publikacji. Aktywności obejmowały wszystkie etapy pracy pisarskiej (gromadzenie danych, prace badawczo-poszukiwawcze, dokumentacyjne, grupowanie informacji), redakcyjnej (przygotowanie, redagowanie tekstu, skład, korekta), poligraficznej oraz dystrybucyjnej i marketingowej. Uczestnicy rozwijali umiejętności cyfrowe (obsługa programów komputerowych wykorzystywanych w genealogii). Projekty realizowane były jako prace grupowe, wieloetapowe, obejmujące różne czynności, w różnych lokalizacjach, dlatego uczestnicy rozwijali też umiejętności organizacyjne. Grupa 5 projektów rozwijała umiejętności: techniczne, informatyczne, matematyczne, niwelując wykluczenie cyfrowe uczestników. Projekty realizowane w archiwach wykształcały umiejętności przeszukiwania skomplikowanych baz danych oraz strukturalizowania informacji, dając wiedzę o standardach pracy archiwisty. Ze względu na wieloetapowość projektów, czy też konieczność stosowania podejścia strategicznego w opiece nad obiektem, wykształcały umiejętności organizacyjne i planistyczne. Nabywanie wiedzy oraz rozwój umiejętności prowadziły do wzrostu samooceny uczestników, mogły być spożytkowane do rozwoju zawodowego, dla dobra społeczności, dla zachowania dziedzictwa.

Efekty takie jak w grupie 4 i 5 mogły być również osiągane w działaniach niezwiązanych z dziedzictwem. Ich główne cele wpisywały się bezpośrednio w układ kluczowych kompetencji. Ich organizatorzy dostrzegli jednak, że praca z zasobem dziedzictwa może zwiększać zainteresowanie uczestnictwem w projekcie (osoby wcześniej zainteresowane historią), ale też poprzez udział w projekcie takie zainteresowanie może się wytworzyć (i w przyszłości procentować w podejmowaniu kolejnych działań na rzecz dziedzictwa). Ponadto projekty stanowią fizyczny efekt pracy (co w projektach dla osób wykluczonych było szczególnie cenne, ponieważ uczestnictwo dawało wymierny rezultat potwierdzający nowe umiejętności). Dodatkowym atutem dziedzictwa był jego autentyzm (praca na autentycznym materiale okazywała się bardziej satysfakcjonująca od np. ćwiczeń językowych opierających się na fikcyjnych tematach i problemach) oraz społecznie użyteczna, gdyż zwiększała dostępność i wiarygodność archiwów. $\mathrm{Z}$ efektów pracy mogły (i mogą) korzystać różne grupy społeczne (społeczność lokalna, naukowcy, ludzie poszukujący swoich korzeni, a mieszkający w dużym oddaleniu od fizycznej lokalizacji archiwów). 


\section{Wnioski}

Z przeprowadzonej analizy wynika, że wykorzystanie układu kluczowych kompetencji do wyznaczania granic działań na podstawie dziedzictwa kulturowego jest niewystarczające, ponieważ opiera się na rezultatach, które w dużej mierze mogą być uzyskiwane w projektach niewykorzystujących dziedzictwa. Znaczenie zaangażowania dziedzictwa kulturowego analizowane poprzez pryzmat kluczowych kompetencji sprowadza się do przedstawienia bardziej zróżnicowanej, interesującej oferty edukacyjnej rozwijającej te kompetencje.

Znaczenie działań edukacyjnych wykorzystujących dziedzictwo przedstawia się wyraźnie i wielowymiarowo w analizie dążenia do celów, dla jakich organizowane są aktywności wynikające z idei LLL. Szczególnie dotyczy to rozwoju osobistego, na który składają się nowa wiedza, umiejętności, kompetencje, realizacja aspiracji, marzeń, rozwój talentów, zainteresowań. Mają one wpływ na polepszenie ogólnego dobrostanu ludzi, sytuacji zawodowej, a w dalszej kolejności włączenie społeczne, rozwój więzi społecznych czy wzrost zaangażowania obywatelskiego. W rezultacie znacznie wykraczają poza standardy podstawowych umiejętności i oczekiwań.

Poprzez uczestnictwo w działaniach wykorzystujących dziedzictwo pojawiają się efekty dodatkowe i efekty o sekwencyjnym charakterze (społeczne, kulturowe, gospodarcze). O tym, która z grup efektów będzie dominująca, decydują indywidualne predyspozycje i oczekiwania uczestników, to jak wartościują (i do czego wykorzystają) oni swoje nowe umiejętności, kompetencje, wiedzę. Jeżeli zainteresowany wytworzy więź emocjonalną z dziedzictwem, odkryje w sobie pasje z nim związane, przypisze dziedzictwu wartości kulturowe, to oddziaływania będą pełniejsze, częściej kalkulacja kosztu nie będzie jedynym kryterium, np. wyboru technik wykorzystywanych podczas remontu. Rozwijać się będą aktywności o charakterze wolontariatu. Mogą wystąpić także sytuacje czysto rynkowego podejścia do dziedzictwa, co nie jest zjawiskiem negatywnym, niekiedy pozwala na przetrwanie zasobu (nowa funkcja czyni go użytecznym). Proces dostosowawczy powinien jednak odbywać się z zachowaniem standardów konserwatorskich, z poszanowaniem wartości kulturowych. Realizacja projektów przyczynia się do rozwijania takich postaw. Dodać należy, że efekty uzyskiwane w projektach wykorzystujących dziedzictwo zależą od zdolności artystycznych i predyspozycji do działań kreatywnych uczestnika projektu.

Poszukując potwierdzenia tezy, że dziedzictwo kulturowe stanowi zasób godny do wykorzystania w działaniach wpisujących się w ideę LLL, należy dodać, że zainteresowanie dziedzictwem powoduje wzrost zainteresowania projektami wykorzystującymi ten zasób (kolejne edycje projektów). Zaangażowanie uczestników ma też wpływ na efekty dodatkowe, niezamierzone na etapie planowania inicjatyw 


\begin{tabular}{|c|c|c|}
\hline \begin{tabular}{|c} 
Edukacja o dziedzictwie \\
(realizowane efekty mogą \\
być tylko z wykorzystaniem \\
dziedzictwa)
\end{tabular} & \begin{tabular}{|c} 
Edukacja poprzez \\
dziedzictwo \\
(wykorzystanie dziedzictwa \\
wzmacnia \\
uzyskiwane efekty) \\
\end{tabular} & $\begin{array}{l}\text { Edukacja dla dziedzictwa } \\
\text { (efekty inne niż edukacyjne) }\end{array}$ \\
\hline \multicolumn{2}{|c|}{ Pierwotny efekt projektu - rozwój osobisty } & \multirow{3}{*}{$\begin{array}{l}\text { Pierwotny efekt projektu: } \\
\text { - zachowanie zasobu dziedzictwa } \\
\text { materialnego i niematerialnego } \\
\text { - polepszenie stanu zachowania } \\
\text { - rozpowszechnienie wiedzy o trady- } \\
\text { cyjnych technikach i materiałach } \\
\text { (ginące zawody) }\end{array}$} \\
\hline \begin{tabular}{|l} 
- głównie wiedza, umie- \\
jętności, kompetencje \\
związane z opieką nad \\
dziedzictwem kulturo- \\
wym i zarządzaniem \\
nim; otwartość na inność \\
- dodatkowo nabycie \\
wybranych kluczowych \\
kompetencji
\end{tabular} & $\begin{array}{l}\text { - głównie cele wpisujące } \\
\text { się w katalog kluczowych } \\
\text { kompetencji } \\
\text { - dodatkowym efektem jest } \\
\text { wiedza o dziedzictwie }\end{array}$ & \\
\hline \multicolumn{2}{|c|}{$\begin{array}{l}\text { Satysfakcja z realizacji pasji i pracy zawodowej } \\
\text { Lepsza samoocena, możliwość samorealizacji }\end{array}$} & \\
\hline \multicolumn{2}{|c|}{ Beneficjent bezpośredni: uczestnik projektu } & $\begin{array}{c}\text { Beneficjent bezpośredni: dziedzictwo } \\
\text { materialne i niematerialne }\end{array}$ \\
\hline \multicolumn{2}{|c|}{$\downarrow$} & $\downarrow$ \\
\hline \multicolumn{2}{|c|}{$\begin{array}{l}\text { Możliwe osiąganie dalszych efektów (dzięki rozwojowi } \\
\text { osobistemu): } \\
\text { - aktywizacja zawodowa (w tym wzrost zamożności) } \\
\text { - włączenie społeczne } \\
\text { - tworzenie więzi społecznych } \\
\text { - zaangażowanie obywatelskie } \\
\text { Z efektów korzystają także beneficjenci pośredni: } \\
\text { społeczności lokalne, instytucje kultury, gospodarka, } \\
\text { władza publiczna, budżet państwa }\end{array}$} & $\begin{array}{l}\text { Możliwe osiąganie dalszych efektów: } \\
\text { - rozpowszechnienie dobrych praktyk } \\
\text { konserwatorskich o tradycyjne formy } \\
\text { wytwarzania i tradycyjne materiały } \\
\text { - odtworzenie rynków zbytu na usługi } \\
\text { i materiały związane z tradycyjnymi } \\
\text { technikami } \\
\text { - zwiększenie dostępności dziedzictwa } \\
\text { (np. archiwa, obiekty) } \\
\text { Z efektów korzystają także benefi- } \\
\text { cjenci pośredni: lokalne społeczności, } \\
\text { członkowie mniejszości kulturowych, } \\
\text { uczniowie, naukowcy, entuzjaści kul- } \\
\text { tury i poszukiwacze wiedzy o historii } \\
\text { rodziny, gospodarka, władza publiczna } \\
\text { budżet państwa, możliwe do osiągnię- } \\
\text { cia są także efekty ekologiczne }\end{array}$ \\
\hline
\end{tabular}

Rys. 1. Efekty projektów edukacyjnych wykorzystujących dziedzictwo kulturowe Źródło: opracowanie własne.

przez ich pomysłodawców (wydanie książki ze zbiorem własnych tekstów dotyczących historii, wolontariat wykorzystujący nową wiedzę i umiejętności: dobrowolna digitalizacja kolejnych archiwaliów, rozwój idei adoptowania zabytków). 
Analizując współczesne problemy społeczne (bierna postawa życiowa wobec pracy, nauki, wykluczenia społeczne), wyraźnie widoczne stają się cechy dziedzictwa, które można wykorzystać, aby zniwelować te problemy. Dziedzictwo budzi emocje, dostarcza nowych przeżyć, pozwala rozwinąć poczucie przynależności kulturowej. Ze względu na bardzo szerokie współczesne definiowanie tego, czym jest dziedzictwo, można stwierdzić, że jego edukacyjny potencjał będzie się poszerzał. Może ono być wykorzystywane do rozwiązywania problemów zarówno grup przesyconych technologią (prace fizyczne z wykorzystaniem tradycyjnych technik, narzędzi, praca z archiwaliami, projekty wymuszające kontakty z ludźmi - gromadzenie archiwów historii mówionej itp.), jak i tych cyfrowo wykluczonych (np. nauka digitalizacji). Ważną cechą dziedzictwa jest też to, że pozwala na takie zindywidualizowanie projektów, aby były one interesujące dla uczestników wywodzących się z określonej kultury. Raz sprawdzone rozwiązania mogą być multiplikowane w innych obszarach z wykorzystaniem lokalnego dziedzictwa.

W projektach wpisujących się w edukację dla multikulturowych społeczności znaczenie dziedzictwa dla osłabiania antagonizmów na tle etnicznym, narodowym jest bardzo ważne (szczególnie jeżeli podziały wynikają ze stereotypów nieznajdujących potwierdzenia w rzeczywistości). Niwelacja wykluczeń przedstawicieli mniejszości daje efekty społeczne, ale w dalszej kolejności także i gospodarcze (zatrudnienie, rozwój postaw przedsiębiorczych). Trzeba jednak pamiętać, że o sukcesie projektów mulitkulturowych decyduje wiele czynników niezależnych od ich organizatorów (np. wydarzenia na świecie, których uczestnikami są przedstawiciele danej kultury). W niektórych przypadkach nie udaje się przełamać barier integracji.

Syntetyczne ujęcie struktury efektów przedstawiono na rys. 1. Prezentuje on trzy wymiary działań edukacyjnych: edukację o dziedzictwie, poprzez dziedzictwo i dla dziedzictwa. Każdy z projektów przywoływał (choć w różnym stopniu) efekty w tych wymiarach. Edukacja o dziedzictwie prowadzona była głównie w projektach z grup 1, 2 i 3, choć jako dodatkowy efekt uczestnicy nabywali także wybrane kluczowe kompetencje. Grupy 4 i 5 osiągały główne cele związane z kluczowymi kompetencjami, zwiększając dodatkowo wiedzę o dziedzictwie. W każdej z grup uczestnicy mogli dążyć do samorealizacji, czerpiąc większą satysfakcję z rozwijania pasji i pracy zawodowej. Niezależnie od efektów edukacyjnych uczestników, każdorazowo projekty przyczyniały się do osiągania określonych celów dla samego dziedzictwa (jego zachowania, polepszenia stanu, zwiększenia dostępności). 


\section{Podsumowanie}

W artykule przybliżono wybrane europejskie inicjatywy, w których idea uczenia się przez całe życie jest powiązana z wykorzystaniem dziedzictwa kulturowego. Jak wykazano, projekty pozwoliły na osiągnięcie wielowymiarowych rezultatów, znacznie wykraczających poza oddziaływania ściśle edukacyjne. Prace wykonywane przez uczestników przyczyniły się do ich rozwoju osobistego, ale także służyły i wciąż służą wszystkim, dla których dziedzictwo ma znaczenie (wartości kulturowe i rynkowe). Wykształcenie potrzeby dbałości o zachowanie historycznych obiektów, technik wytwarzania stało się dla wielu uczestników społecznym obowiązkiem, ale również nawykiem zawodowym, dlatego przyczyniają się oni do zachowania zasobów dziedzictwa, a także przekazują wiedzę o jego wartościach i umiejętnościach, które nabyli. Długofalowe oddziaływania projektów wynikają także z możliwości korzystania z ich efektów przez przyszłe pokolenia. Tym samym edukacja poprzez dziedzictwo i o dziedzictwie staje się elementem polityki zrównoważonego rozwoju, czerpiąc z wartości i zasobów odziedziczonych po przeszłych pokoleniach.

\section{Literatura}

Affelt W. (2008), Dziedzictwo techniki w kontekście rozwoju zrównoważonego (w:) Wspótczesne problemy teorii konserwatorskiej w Polsce, red. B. Szmygin, ICOMOS, Warszawa-Lublin.

Ashworth G.J. (2007), Sfragmentaryzowane dziedzictwo: sfragmentaryzowany instrument sfragmentaryzowanej polityki (w:) Dziedzictwo kulturowe w XXI wieku. Szanse i wyzwania, red. M. Murzyn, J. Purchla, Międzynarodowe Centrum Kultury, Kraków.

Bauer Ch., Alaerts L., Van Dessel J., Wouters R. (2011), AQUEDUCT - Acquiring Key Competences through Heritage Education, Landcommanderij Alden Biesen, Bilzen.

Birgisdóttir B.B. (2014), A New Perspective on Life: Unemployment and the Benefits of Heritage Learning Outcomes (w:) Implementing Heritage Learning Outcomes, red. D. Christidou, Jamtli Förlag, Östersund.

Bowitz E., Ibenholt K. (2009), Economic Impact of Cultural Heritage. Research and Perspectives, ,Journal of Cultural Heritage”, vol. 10, nr 1, https://doi.org/10.1016/ j.culher.2008.09.002.

Christidou D., Hansen A. (2015), Volunteers in Museums in Denmark, Sweden and Norway: A Comparative Report. Pride, Joy and Surplus Value, NCHLC, Östersund.

Clausen N.F., Marker H.J. (2000), The Danish Data Archive (w:) Handbook of International Historical Microdata for Population Research, eds P.K. Hall, R. McCaa, G. Thorwaldsen, The International Microdata Access Group, Minneapolis Minn.

The Conservation Volunteers. Join in, Feel Good (2016), The Community Volunteering Charity, Doncaster. 
Deklaracja o uczeniu się dorosłych (1997), V Światowa Konferencja nt. Edukacji Dorosłych, Hamburg.

Edukacja muzealna w Polsce. Sytuacja, kontekst, perspektywy rozwoju. Raport o stanie edukacji muzealnej w Polsce (2012), red. M. Szeląg, NIMOZ, Warszawa.

Fristrup T., Kling S., Sonne L., Zipsane H. (2012), Heritage Learning Outcomes in the Nordic and Baltic Area, NCHL, Östersund.

González J.Š. (2013), Trends in Practical Heritage Learning. Study in Europe in 2012, NCHLC, Östersund.

Graham F. (2009), New Heritage Frontiers (w:) Heritage and Beyond, Council of Europe Publishing, Strasbourg.

Gustaffson Ch. (2011), The Halland Model, Gothenburg Studies in Conservation No. 24, Göteborg.

Haapalainen R., Jokela J., Niemi S.M., Perälä A. (2016), Annual Awards in Museum Pedagogy 2006-2015 (w:) New Approaches NOW. From Museum Education to Audience Engagement, ed. E. Johansson, Pedaali, Helsinki.

Haverkamp L., Strauch S. (2017), Jugendbauhütten. Freiwilliges Soziales Jahr in der Denkmalpflege. Jahresbericht 2016, DSD, Bonn.

Howard P. (2009), Historic Landscapes and the Recent Past: Whose History? (w:) Valuing Historic Environments, red. L. Gibson, J. Pendlebury, Aashgate, Farnham-Burlington.

Hunt A., Kershaw A. (2013), Sustainable Development through Heritage and Education: The New Peterborough Effect (w:) Rethinking Education, red. G. Beyens i in., Brussels.

The Impact of Culture on Creativity (2009), A Study Prepared for the European Commission, http://www.keanet.eu/docs/impactculturecreativityfull.pdf (data dostępu: 31.01.2018).

Innocent N. (2009), How Museums, Libraries and Archives Contribute to Lifelong Learning, IFLL Sector Paper 10, MLAC, National Institute of Adult Continuing Education, Leicester.

Jackson A., Kidd J. (2008), Performance as a Medium of Learning in Museums and at Heritage Sites, Centre for Applied Theatre Research, Manchester.

Jackson N. (2010), Enabling a More Complete Education (w:) Enabling a More Complete Education. Encouraging, Recognizing and Valuing Life-wide Learning in Higher Education, red. N. Jackson, R. Law, University of Surrey, Guildford.

Jensen B. (2014), How Can Family History and Ancient Handwriting Add to a Happy Life: Adult Self-organized Groups in Aalborg City Archives (w:) Implementing Heritage Learning Outcomes, red. D. Christidou, Jantli Förlag, Östersund.

Key Competences for Lifelong Learning. A European Framework (2006), 2006/962/EC.

Kling S. (2010), Assessing Heritage Learning Outcomes. How Do We Do It - and Why? Heritage, Regional Development and Social Cohesion International Conference, Östersund.

Konwencja ramowa Rady Europy w sprawie znaczenia dziedzictwa kulturowego dla społeczeństwa (2005), Faro.

Konwencja w sprawie ochrony światowego dziedzictwa kulturalnego i naturalnego (1972), UNESCO, Paryż.

Learning in Museums and Young People (2015), NEMO-LEM Working Group Study, https://www.ne-mo.org/fileadmin/Dateien/public/topics/Audience_Development/ Museums_and_Young_People_NEMO_LEMWG_study_2015.pdf (data dostępu: 31.01.2018). 
Lifelong Learning and Well-being: An Analysis of the Relationship between Adult Learning and Subjective Well-being, ,IFLL Public Value Paper” 2009, nr 3.

Lifelong Learning for All (1996), OECD, Paris.

Lifelong Learning in Museums. A European Handbook (2007), red. K. Gibbs, M. Sani, J. Thompson, EDISAI, Ferrara.

Making a European Area of Lifelong Learning a Reality (2001), Komunikat Komisji Europejskiej, COM (2001) 678 final.

Millennials. Fueling the Experience Economy. Report (2014), Eventbrite, https://www. eventbrite.com/blog/academy/millennials-fueling-experience-economy/ (data dostępu: 31.01.2018).

Murzyn-Kupisz M. (2012), Dziedzictwo kulturowe a rozwój lokalny, Wydawnictwo Uniwersytetu Ekonomicznego w Krakowie, Kraków.

Nora P. (1989), Between Memory and History, Les Lieux de mémoire, „Representations”, Spring, 26, https://doi.org/10.2307/2928520.

Stebbins R. (2015), Serious Leisure: A Perspective for Our Time, Transaction Publishers, New Brunswick, London.

Sunderland Bowe J.A. (2016), The Creative Museum - Analysis of Selected Best Practices from Europe, Heritec Education Consulting.

Throsby D. (2010), Ekonomia i kultura, NCK, Warszawa.

Towse R. (2002), The Cultural Economy of Heritage (w:) The Economics of Heritage. A Study in the Political Economy of Culture in Sicily, red. I. Rizzo, T. Towse, E. Elgar, Cheltenham.

Zipsane H. (2008), Lifelong Learning through Heritage and Art (w:) The Routledge International Handbook of Lifelong Learning, red. P. Jarvis, Routledge, London-New York.

Zipsane H. (2012), Untraditional Creative Partnerships - Seven Wonders of Arts and Culture in Education, Education and Learning Workgroup, The European Commission.

Zipsane H. (2013), Policy Synergy: The Contribution of Culture to Lifelong Learning (w:) Rethinking Education, red. G. Beyens, M. Ramos, E. Zipsane i T. Ophuysen, Brussels.

\section{The Role of Cultural Heritage in Lifelong Learning - Selected Examples from European Countries}

(Abstract)

The article reviews the literature showing European experiences in executing educational projects using cultural heritage, analyses and aggregates their effects, assesses how the use of heritage increases educational effects and asks whether it contributes to the implementation of other ones. The analysis showed that activities using heritage implement objectives for which the idea of lifelong learning is carried out. The personal development of participants promotes social inclusion, the development of social bonds, civic engagement and the development of entrepreneurial attitudes. Particularly good effects are achieved when working with people from excluded groups, creative people and those interested in culture and history. Regardless of educational effects, projects contribute to the preservation and improvement of cultural heritage.

Keywords: cultural heritage, culture, lifelong learning, key competences. 